\title{
Total body water and fat-free mass: evaluation of equations based on bioelectrical impedance analysis in infants and young children in India
}

\author{
Bandana Sen ${ }^{1}$, Dilip Mahalanabis ${ }^{1}$, Anura V. Kurpad ${ }^{2}$, Saijuddin Shaikh ${ }^{1}$ and Kaushik Bose ${ }^{3}$ \\ ${ }^{1}$ Society for Applied Studies, CF-198, Salt Lake City, Sector 1, Kolkata 700 064, India \\ ${ }^{2}$ Institute of Population Health and Clinical Research, St John's Medical College, St John's National Academy of Health Sciences, \\ Bangalore 560 034, India \\ ${ }^{3}$ Department of Anthropology, Vidyasagar University, Paschim Midnapore 721 102, India
}

(Received 10 August 2009 - Revised 25 January 2010 - Accepted 26 January 2010 - First published online 1 March 2010)

The association of early postnatal growth with diseases in adults such as hypertension, type 2 diabetes and CHD has generated interest in studying postnatal growth. Bioelectrical impedance analysis (BIA) is a useful measure to estimate total body water (TBW) and fat-free mass (FFM). We evaluated three published equations (Fjeld et al. (Pediatr Res (1990) 27, 98-102), Bocage (MSc Thesis (1988) University of West Indies) and Kushner et al. (Am J Clin Nutr (1992) 56, 835-839) to measure TBW and derived FFM based on BIA, using ${ }^{2} \mathrm{H}_{2} \mathrm{O}$ dilution as a reference method for suitability in infants in India. In a cross-sectional study in seventy-eight apparently healthy infants aged 6-24 months from the urban poor attending an immunisation clinic at a hospital in Kolkata, we measured their length to the nearest $0.1 \mathrm{~cm}$, weight to the nearest $10 \mathrm{~g}$, resistance at $50 \mathrm{kHz}$ using BIA and TBW using ${ }^{2} \mathrm{H}_{2} \mathrm{O}$ dilution. TBW was derived using three published BIA-based equations and compared with TBW using ${ }^{2} \mathrm{H}_{2} \mathrm{O}$ dilution. Based on the BIA equations of Fjeld et al., Bocage and Kushner et al., the mean TBW values were $2.46 \%$ $(P<0.001), 4.62 \%(P<0.001)$ and $9.50 \%(P<0.001)$ lower than the reference ${ }^{2} \mathrm{H}_{2} \mathrm{O}$ method, respectively. All three published BIA-based equations consistently underestimated the TBW and FFM and appeared inadequate for studying infants in India. The equation described by Fjeld et al. gave the smallest deviation from the reference method and may be used for field studies. New equations based on population-specific data are desirable for a more precise measure of TBW.

Total body water: Fat-free mass: ${ }^{2}$ H-labelled water: Dilution techniques: Bioelectrical impedance analysis: Infants

Practical methods for use in clinics and in the field to measure fat-free mass (FFM) or lean body mass in infants and children are largely based on anthropometry (such as height or length and weight) and recently introduced bioelectrical impedance analysis (BIA) techniques. Based on these methods, equations have been developed for children in both developed and developing countries. We could identify two equations ${ }^{(1,2)}$ based on length or height and weight and three based on the BIA technique (Fjeld et al. ${ }^{(3)}$, Bocage ${ }^{(4)}$ and Kushner et $a{ }^{\left({ }^{(5)}\right)}$ for infants and children. Before we can use any of these equations with confidence on a population different from those on whom these equations were developed, it is important to validate them.

We have earlier reported our evaluation of the two equations above based on length or height and weight using stable-isotope $\left({ }^{2} \mathrm{H}_{2} \mathrm{O}\right)$ dilution as the reference method ${ }^{(6)}$. However, equations based on conventional anthropometry, i.e. length and weight, have the inherent limitation in that they do not critically distinguish between FFM and fat mass. On the other hand, the theoretical basis of bioelectrical impedance analysis indicates that it is well suited to assess total body water $(\mathrm{TBW})^{(7)}$. The method is based on the phenomenon that only water (containing electrolytes) in the human body can conduct electricity. Fat is relatively devoid of water and restricts the flow of current through it. At any given current frequency the impedance of a cylindrical system is a function of length and cross-sectional area. In a steady-state condition, TBW correlates well with FFM. The BIA equipment is easily carried to the community for population-based studies. In the present study, we have evaluated three published equations based on BIA for TBW in children in India aged between 6 and 24 months, using the ${ }^{2} \mathrm{H}_{2} \mathrm{O}$ dilution technique as the reference method. The present report is based on our analysis of the data generated in our study reported earlier ${ }^{(6)}$.

\section{Subjects and methods}

Subjects

As described previously ${ }^{(6)}$, eighty-six children, aged 6-24 months, participated in the study. The study was done

Abbreviations: BI-1, BIA-based equation of Fjeld et al.; BI-2, BIA-based equation of Bocage; BI-3, BIA-based equation of Kushner et al.; BIA, bioelectrical impedance analysis; FFM, fat-free mass; FFMkg, FFM measured in kg; TBW, total body water; TBWkg, TBW measured in kg.

* Corresponding author: Dr Dilip Mahalanabis, fax +91 332337 0709, email sas_kolkata@vsnl.net 
in apparently healthy children from among the urban poor attending an immunisation clinic of a large charitable government hospital in the city of Kolkata where free service is provided. The immunisation clinic is held once per week. Each week we interviewed the first four mothers who registered their children in the weekly clinic and we aimed to recruit up to two children each week. The recruitment was spread over a period of 1 year.

The eligibility criteria for inclusion in the study were: aged 6-24 months of either sex; absence of illness during the preceding 1 month; absence of gross congenital anomalies and chronic diseases; parents' willingness to participate. These children were of low socio-economic status, and records on birth weight and gestation were not available for consideration. The birth dates were precise as they were based on birth certificates. Written informed consent was obtained from the parents.

\section{Sample size}

As described previously ${ }^{(6)}$, the sample size depended on the magnitude of deviation from zero of the difference in the measured quantity derived by the reference method (i.e. by ${ }^{2} \mathrm{H}_{2} \mathrm{O}$ dilution) and the method under study and its $\mathrm{CI}$, that would be acceptable for the purpose that the method would be used and therefore could only be indicative. The comparisons were paired, i.e. the results from the two methods on each subject were compared. We calculated the sample size to detect $1.5 \%$ or more deviation from zero difference with a standard deviation of 2 . To detect this degree of deviation with $95 \% \mathrm{CI}$ and $90 \%$ power we needed a sample of seventyone subjects in each group ${ }^{(8)}$. Since the same subject would provide data of TBW by both the criterion method and the comparison methods the calculated sample size remained the same (i.e. seventy-one subjects). We added $12 \%$ to this number for possible dropout to give a sample size of eighty subjects.

\section{Bioelectrical impedance analysis}

BIA measures impedance of the body to a small electric current. The generic theoretical model treats the body as a single cylinder, with measurements made between electrodes placed manually on the wrist and ankle. Adjustment of bioelectrical data for height allows estimation of TBW. The theoretical relationship ${ }^{(9)}$ is as follows:

$$
\mathrm{V} \alpha \mathrm{L}^{2} / \mathrm{Z}
$$

where $\mathrm{V}$ is the volume of the body water in the subject, $\mathrm{Z}$ is impedance and $\mathrm{L}$ is the length of the subject. In the present study, impedance and resistance were measured with a multifrequency bioelectrical impedance analyser (Xitron model 4000b; Xitrons Technologies Inc., San Diego, CA, USA) using a single frequency of $50 \mathrm{kHz}$. Children with dry light clothes lay supine ${ }^{(10,11)}$ with arms apart from the body and legs separated so that the thighs did not touch. After cleaning the skin contact area with alcohol, one pair of electrodes (foil disposable $5 \mathrm{~cm}^{2}$ electrocardiogram (ECG) electrodes) was placed on the dorsal surfaces of the right hand at the distal metacarpal joints and between the distal prominence of the right radius and ulna. Another pair was placed at the distal metatarsal joints and between the lateral malleoli of the right foot.

\section{Anthropometric measurements}

The anthropometric measurements were made using recommended protocols ${ }^{(12,13)}$ and are briefly described. The measurements were taken on the same day that the infant underwent the ${ }^{2} \mathrm{H}_{2} \mathrm{O}$ dilution and BIA procedures.

Length. Recumbent length was measured with a wooden measuring board as described earlier ${ }^{(14)}$. The board was made sufficiently broad to cover the shoulder blades. The reading was taken to the nearest $0 \cdot 1 \mathrm{~cm}$.

Weight. Weight was measured nude, using an electronic platform balance (model no. L111A; Avery India Ltd, Ballabgarh, India) with a precision of $10 \mathrm{~g}$. The balance was checked regularly for accuracy using standard weights.

\section{${ }^{2} \mathrm{H}$-labelled water dilution method}

${ }^{2} \mathrm{H}_{2} \mathrm{O}$, water with a stable isotope of hydrogen, was used and has been described previously ${ }^{(6)}$. This measurement took place between 09.00 and 14.00 hours. Because of their age, the infants were not fasted. A vast majority of them were breast-fed $(88 \%)$. No food other than breast-feeding was allowed for $3 \mathrm{~h}$ before administrating the ${ }^{2} \mathrm{H}_{2} \mathrm{O}$. Breast-feeding was stopped $1 \mathrm{~h}$ before administrating the ${ }^{2} \mathrm{H}_{2} \mathrm{O}$. As expected, the infants were normally hydrated, as judged clinically at the time of the test. Children's baseline saliva was collected by a disposable syringe. We took a measured volume of ${ }^{2} \mathrm{H}_{2} \mathrm{O}$ (99.9\%; Sigma, St Louis, MO, USA) approximately equivalent to $50 \mathrm{mg} / \mathrm{kg}$ body weight in a disposable container $\left({ }^{2} \mathrm{H}_{2} \mathrm{O}\right.$ specific gravity $\left.=1 \cdot 107\right)$. We weighed the ${ }^{2} \mathrm{H}_{2} \mathrm{O}$ dose using a precision balance and the weight with an accuracy of $0.1 \mathrm{mg}$ was recorded and used in calculating TBW. It was then mixed with $20 \mathrm{ml}$ distilled water and the child drank it from a disposable syringe. The empty container was rinsed with two consecutive lots of $15 \mathrm{ml}$ distilled water and the child drank both lots from the same disposable syringe. Time was allowed to equilibrate the ${ }^{2} \mathrm{H}_{2} \mathrm{O}$ into the body fluid. No food or fluid including breast milk and water was permitted during the equilibration period of $3 \mathrm{~h}$. At the end of the equilibration period the second sample of saliva was collected and analysed for ${ }^{2} \mathrm{H}$-labelled water using a duelinlet mass spectrometer (Europa Scientific, Crewe, Ches, $\mathrm{UK}$ ), using the $\mathrm{Zn}$ reduction technique. The results of ${ }^{2} \mathrm{H}_{2} \mathrm{O}$ concentration in the saliva samples were used for calculating the TBW.

The following equation was used ${ }^{(6)}$ :

$$
\begin{aligned}
\operatorname{TBW}(\mathrm{kg})= & (\text { mol TBW } \\
& \left.\times \text { molecular weight of } \mathrm{H}_{2} \mathrm{O}(\text { i.e. } 18 \cdot 0153)\right) / 1000 .
\end{aligned}
$$

TBW (mol) was calculated as follows:

$$
\begin{gathered}
\text { TBW }(\mathrm{mol})=\left(\mathrm{F}_{1} \times \mathrm{N}_{1}\right) /\left(\mathrm{F}_{2} \times 1 \cdot 041\right) . \\
\mathrm{F}_{1}=\left(\text { concentration of }{ }^{2} \mathrm{H}_{2} \mathrm{O} \text { in atom per cent }(\text { i.e. } 99 \cdot 9)\right. \\
\left.\times 10^{6} / 100-150\right) \text { parts per million }(\mathrm{ppm}) \text { of }{ }^{2} \mathrm{H}_{2} \mathrm{O} . \\
\mathrm{F}_{2}=\text { ppm after dose }- \text { ppm before dose of }{ }^{2} \mathrm{H}_{2} \mathrm{O} \\
\text { (using concentrations in saliva samples). }
\end{gathered}
$$


Table 1. Characteristics of subjects

\begin{tabular}{|c|c|c|c|c|c|c|c|c|c|c|}
\hline \multirow[b]{2}{*}{ Characteristics } & \multicolumn{5}{|c|}{ Boys ( $n$ 36) } & \multicolumn{5}{|c|}{ Girls ( $n$ 42) } \\
\hline & Mean & SD & Range & $n$ & $\%$ & Mean & SD & Range & $n$ & $\%$ \\
\hline Age & $15 \cdot 3$ & $5 \cdot 6$ & $6 \cdot 2-23 \cdot 8$ & & & $16 \cdot 3$ & $5 \cdot 3$ & $7 \cdot 0-23 \cdot 6$ & & \\
\hline$<12$ months & & & & 13 & 36 & & & & 10 & 32 \\
\hline$\geq 12$ months & & & & 23 & 64 & & & & 24 & 76 \\
\hline Body weight $(\mathrm{kg})$ & 8.9 & $1 \cdot 3$ & $6 \cdot 4-12 \cdot 1$ & & & $8 \cdot 8$ & 1.4 & $6.2-11.9$ & & \\
\hline Length (cm) & $76 \cdot 6$ & $6 \cdot 0$ & $65 \cdot 5-86 \cdot 5$ & & & $76 \cdot 0$ & $6 \cdot 1$ & $63 \cdot 8-86 \cdot 0$ & & \\
\hline Resistance $(\Omega)^{*}$ & $797 \cdot 0$ & $96 \cdot 6$ & $657-1025$ & & & 814.5 & 63.1 & $688-998$ & & \\
\hline WHZ† & -1.37 & 1.05 & & & & -1.01 & 0.70 & & & \\
\hline $\mathrm{WHZ}<-2$ & & & & 10 & 28 & & & & 3 & 7 \\
\hline$W H Z \geq-2$ and $<-1$ & & & & 14 & 39 & & & & 17 & 41 \\
\hline$W H Z \geq-1$ & & & & 12 & 33 & & & & 22 & 52 \\
\hline WAZ† & -1.57 & $1 \cdot 10$ & & & & -1.33 & 0.95 & & & \\
\hline$W A Z<-2$ & & & & 12 & 33 & & & & 10 & 24 \\
\hline$W A Z \geq-2$ and $<-1$ & & & & 16 & 45 & & & & 18 & 43 \\
\hline$W A Z \geq-1$ & & & & 8 & 22 & & & & 14 & 33 \\
\hline $\mathrm{HAZ} \dagger$ & -0.87 & 1.05 & & & & -0.87 & $1 \cdot 22$ & & & \\
\hline $\mathrm{HAZ}<-2$ & & & & 4 & 11 & & & & 7 & 17 \\
\hline $\mathrm{HAZ} \geq-2$ and $<-1$ & & & & 10 & 28 & & & & 13 & 31 \\
\hline$H A Z \geq-1$ & & & & 22 & 61 & & & & 22 & 52 \\
\hline
\end{tabular}

WHZ, weight-for-length standard deviation score; WAZ, weight-for-age standard deviation score; HAZ, height-for-age standard deviation score.

${ }^{*}$ As measured by bioelectric impedance analysis at $50 \mathrm{kHz}$.

†WHZ, WAZ and HAZ standard deviation scores compared with National Center for Health Statistics (NCHS) reference (Epi Info, version 6.0; Centers for Disease Control and Prevention, Atlanta, GA, USA).

$\mathrm{N}_{1}=$ dose of ${ }^{2} \mathrm{H}_{2} \mathrm{O}$ (in g)/molecular weight of ${ }^{2} \mathrm{H}_{2} \mathrm{O}$ (i.e. 20.0274).

In using ${ }^{2} \mathrm{H}$ for estimating $\mathrm{TBW}$, it should be noted that this isotope undergoes some exchange with non-aqueous hydrogen and a correction factor of 1.041 was used. The FFM was calculated as TBW divided by an age- and sex-specific hydration factor for FFM and for this age group that ranged from 80.7 to $77 \cdot 0$ for boys and from 80.7 to 78.0 for girls ${ }^{(15)}$.

\section{Bioelectrical impedance analysis-based published equations}

The prediction equations for TBW (measured in $\mathrm{kg}$; TBWkg) using weight, length and resistance that we evaluated in the present study are given below.

BIA-based equation of Fjeld et al. ${ }^{(3)}$ (BI-1) on Peruvian children aged 3-30 months:

$$
\mathrm{TBWkg}=0.76+0.18 \times \mathrm{H}^{\wedge} 2 / \mathrm{R}+0.39 \times \mathrm{W} .
$$

BIA-based equation of Bocage ${ }^{(4)}(\mathrm{BI}-2)$ on Jamaican children aged 3-18 months:

$$
\mathrm{TBWkg}=(0.418 \times \mathrm{W}+1936 / \mathrm{R}+0 \cdot 8649) \times \mathrm{H} / 100 .
$$

BIA-based equation of Kushner et al. ${ }^{(5)}$ (BI-3) on children aged 1-60 months:

$$
\mathrm{TBWkg}=0.59 \times \mathrm{H}^{\wedge} 2 / \mathrm{R}+0.065 \times \mathrm{W}+0.04,
$$

where $\mathrm{H}$ is length in $\mathrm{cm}, \mathrm{W}$ is weight in $\mathrm{kg}$ and $\mathrm{R}$ is resistance at $50 \mathrm{kHz}$.

The equation of Kushner et al. ${ }^{(5)}$ was derived on preschool children of Lima, Peru and on premature neonates in the USA.

We used the same age- and sex-specific hydration factors for $\mathrm{FFM}^{(15)}$ for calculating $\mathrm{FFM}$ from TBW derived by these BIA-based equations as was done for TBW measured by the ${ }^{2} \mathrm{H}_{2} \mathrm{O}$ dilution technique.

\section{Statistical analysis}

Epi Info (version 6.0; Centers for Disease Control and Prevention, Atlanta, GA, USA) and Stata (version 7.0; StataCorp LP, College Station, TX, USA) were used for data entry and statistical analysis. For anthropometry data, a software package based on National Center for Health Statistics database as provided with the Epi Info software was used. As is conventionally done, correlation and regression analysis was used to compare the TBW based on BIA with the reference method, i.e. the ${ }^{2} \mathrm{H}_{2} \mathrm{O}$ dilution technique. We plotted the results along the 'line of equality' (i.e. the line at a $45^{\circ}$ angle) to visually examine the concordance ${ }^{(16)}$. Further, the difference in TBW for each subject between each of the three BIA equations and ${ }^{2} \mathrm{H}_{2} \mathrm{O}$ dilution (paired data) were evaluated for their difference from zero by $t$ test. The mean of the difference $\pm 2 \mathrm{SD}$ was calculated to derive the range within which $95 \%$ of the values were expected to $\operatorname{lie}^{(16)}$.

\section{Ethical approval}

The present study was conducted according to the guidelines laid down in the Declaration of Helsinki and all procedures involving human subjects were approved by the Ethics Review Committee of the Society for Applied Studies, Kolkata, India. Written informed consent was obtained from the parents of all subjects.

\section{Results}

Eighty-six children participated in the present study and were described in an earlier study ${ }^{(6)}$. In eight of them, the ${ }^{2} \mathrm{H}_{2} \mathrm{O}$ procedures were incomplete because of vomiting or being fed during the equilibration period. They were dropped from the study. The study infants were predominantly 
Table 2. Total body water (TBW) and fat-free mass (FFM) in $\mathrm{kg}$ and as percentage body weight derived by the three equations under study and by the ${ }^{2} \mathrm{H}_{2} \mathrm{O}$ dilution technique (reference method)

(Mean values and standard deviations)

\begin{tabular}{|c|c|c|c|c|c|c|c|c|c|c|c|c|c|c|}
\hline & \multicolumn{7}{|c|}{ TBW } & \multicolumn{7}{|c|}{ FFM } \\
\hline & \multicolumn{2}{|c|}{ Total $(n 78)$} & \multicolumn{2}{|c|}{ Boys ( $n$ 36) } & \multicolumn{2}{|c|}{ Girls ( $n$ 42) } & \multirow[b]{2}{*}{$P^{\star}$} & \multicolumn{2}{|c|}{ Total $(n 78)$} & \multicolumn{2}{|c|}{ Boys ( $n$ 36) } & \multicolumn{2}{|c|}{ Girls ( $n$ 42) } & \multirow[b]{2}{*}{$P^{*}$} \\
\hline & Mean & SD & Mean & SD & Mean & SD & & Mean & SD & Mean & SD & Mean & SD & \\
\hline \multicolumn{15}{|c|}{${ }^{2} \mathrm{H}_{2} \mathrm{O}$ dilution } \\
\hline $\mathrm{Kg}$ & $5 \cdot 75$ & 0.84 & $5 \cdot 89$ & 0.92 & $5 \cdot 63$ & 0.76 & - & $7 \cdot 31$ & $1 \cdot 11$ & $7 \cdot 49$ & $1 \cdot 21$ & $7 \cdot 15$ & 1.00 & - \\
\hline$\%$ & 65.04 & $5 \cdot 64$ & 65.91 & 4.40 & 64.29 & $6 \cdot 48$ & 0.21 & $82 \cdot 64$ & $7 \cdot 22$ & 83.79 & 6.04 & 81.65 & 8.04 & 0.19 \\
\hline \multicolumn{15}{|c|}{$\mathrm{BIA}(\mathrm{BI}-1)$} \\
\hline $\mathrm{Kg}$ & 5.54 & 0.74 & 5.59 & 0.72 & 5.49 & 0.76 & - & 7.05 & 0.98 & $7 \cdot 12$ & 0.96 & 7.00 & 1.00 & - \\
\hline$\%$ & 62.58 & 1.88 & $62 \cdot 72$ & 1.83 & 62.46 & 1.94 & 0.56 & $79 \cdot 65$ & $2 \cdot 34$ & $79 \cdot 79$ & $2 \cdot 35$ & 79.54 & $2 \cdot 35$ & 0.65 \\
\hline \multicolumn{15}{|c|}{ BIA (BI-2) } \\
\hline $\mathrm{Kg}$ & $5 \cdot 37$ & 0.85 & 5.43 & 0.82 & $5 \cdot 31$ & 0.88 & - & $6 \cdot 84$ & $1 \cdot 12$ & 6.91 & $1 \cdot 10$ & 6.77 & $1 \cdot 15$ & - \\
\hline$\%$ & 60.42 & $2 \cdot 10$ & $60 \cdot 74$ & $2 \cdot 13$ & $60 \cdot 14$ & $2 \cdot 07$ & 0.21 & $76 \cdot 92$ & 3.02 & $77 \cdot 19$ & $3 \cdot 20$ & $76 \cdot 60$ & $2 \cdot 86$ & 0.32 \\
\hline \multicolumn{15}{|c|}{$\mathrm{BIA}(\mathrm{BI}-3)$} \\
\hline $\mathrm{Kg}$ & 4.93 & 0.83 & 5.03 & $0 \cdot 82$ & 4.85 & 0.83 & - & $6 \cdot 27$ & 1.08 & 6.39 & 1.08 & $6 \cdot 17$ & 1.09 & - \\
\hline$\%$ & 55.54 & $4 \cdot 10$ & $56 \cdot 24$ & $4 \cdot 14$ & 54.93 & 4.01 & 0.16 & $70 \cdot 62$ & 5.25 & 71.44 & $5 \cdot 31$ & 69.91 & $5 \cdot 15$ & 0.20 \\
\hline
\end{tabular}

$\mathrm{BIA}$, bioelectrical impedance analysis; $\mathrm{BI}-1$, BIA-based equation of Fjeld et al. ${ }^{(3)} ; \mathrm{BI}-2, \mathrm{BIA-based} \mathrm{equation} \mathrm{of} \mathrm{Bocage}{ }^{(4)} ; \mathrm{BI}-3$, BIA-based equation of Kushner et al. ${ }^{(5)}$.

${ }^{*}$ Between boys and girls.

breast-fed $(88 \%)$. They came from among the urban poor. Only $10 \%$ of the families lived in houses of permanent structure. A total of $65 \%$ lived and cooked in one room. The median monthly family income was 40 US\$. Of the mothers, $13 \%$ were illiterate, $35 \%$ had $1-5$ years, $42 \%$ had $6-10$ years and the remaining $10 \%$ had more than 10 years of school education. Characteristics of the study children are shown in Table 1. Weight-for-age, length-for-age and weight-for-length standard deviation scores suggest some degree of underweight, wasting and stunting. Using the three published equations of BI-1, BI-2 and BI-3 and by ${ }^{2} \mathrm{H}_{2} \mathrm{O}$ dilution we derived TBW in $\mathrm{kg}$ (TBWkg) (Table 2). Based on BI-1, BI-2 and BI-3 equations the mean TBW values were $2.46 \% \quad(P<0.001), 4.62 \% \quad(P<0.001)$ and $9.50 \%$ $(P<0.0001)$ lower than the reference ${ }^{2} \mathrm{H}_{2} \mathrm{O}$ method, respectively. Calculated TBW and FFM using the ${ }^{2} \mathrm{H}_{2} \mathrm{O}$ dilution technique and the three BIA equations are shown in Table 2. The mean FFM values derived by BI-1, BI-2 and BI-3 were $2.98 \% \quad(P=0.0002), \quad 5.72 \% \quad(P<0.001)$ and $12.02 \%$ $(P<0.001)$ lower than the reference method, respectively (Table 3). However, there was no statistical sex difference in FFM or TBW. The mean and standard deviations of paired values of the difference in FFM in $\mathrm{kg}$ (FFMkg) and as percentage of body weight between those derived by ${ }^{2} \mathrm{H}_{2} \mathrm{O}$ dilution and each of the three equations under study and $95 \%$ CI of the difference are shown in Table 3. For comparison we have also given in Table 3 the results comparing the ${ }^{2} \mathrm{H}_{2} \mathrm{O}$ reference method and each of the two anthropometry-based equations reported previously ${ }^{(6)}$. The two anthropometrybased equations gave better agreement with the reference method than any of the three BIA-based equations. FFMkg derived by the equation BI-1 gave comparatively better agreement with the reference method than either of the other two equations; the $95 \%$ limits of agreement with the reference method (i.e. mean difference $\pm 2 \mathrm{SD}$ ) were -0.87 to 1.38 , -0.66 to 1.60 and -0.15 to 2.22 for BI-1, BI-2 and BI-3, respectively. Distribution of points for TBWkg along the line of identity (i.e. at $45^{\circ}$ ) between the ${ }^{2} \mathrm{H}_{2} \mathrm{O}$ and BI-1, BI-2 and BI-3 method, respectively, are shown in Fig. 1(a)-(c). Similarly, FFMkg values are plotted in Fig. 2(a)-(c). BlandAltman plots of the differences in TBWkg in each participant between ${ }^{2} \mathrm{H}_{2} \mathrm{O}$ and each of the equations BI-1, BI-2 and BI-3 against average TBWkg are shown in Fig. 1(d)-(f); mean differences were $0 \cdot 21,0 \cdot 38$ and $0 \cdot 82$, respectively.

Similarly for FFMkg, the differences were plotted in Fig. 2(d)-(f); mean differences were 0.25, 0.47 and 1.04,

Table 3. Difference in fat-free mass (FFM) (of paired values) in $\mathrm{kg}$ and as percentage body weight between those derived by ${ }^{2} \mathrm{H}_{2} \mathrm{O}$ dilution and by each of the three equations under study and each of the two equations based on anthropometry as published previously ${ }^{(6)}$

(Mean values and standard deviations and $95 \%$ confidence intervals of the difference)

\begin{tabular}{|c|c|c|c|c|c|c|c|c|}
\hline \multirow[b]{2}{*}{ Difference between methods } & \multicolumn{4}{|c|}{ Difference (kg) } & \multicolumn{4}{|c|}{ Difference (percentage body weight) } \\
\hline & Mean & SD & $95 \% \mathrm{Cl}$ & $P^{\star}$ & Mean & SD & $95 \% \mathrm{Cl}$ & $P^{*}$ \\
\hline${ }^{2} \mathrm{H}_{2} \mathrm{O}-\mathrm{Bl}-1$ & 0.25 & 0.56 & $0.13,0.38$ & 0.0002 & 2.98 & $6 \cdot 29$ & $1.57,4.40$ & - \\
\hline${ }^{2} \mathrm{H}_{2} \mathrm{O}-\mathrm{BI}-2$ & 0.47 & 0.57 & $0.34,0.60$ & $<0.001$ & $5 \cdot 72$ & $6 \cdot 60$ & $4 \cdot 23,7 \cdot 21$ & - \\
\hline${ }^{2} \mathrm{H}_{2} \mathrm{O}-\mathrm{BI}-3$ & 1.04 & 0.59 & $0.90,1.17$ & $<0.001$ & $12 \cdot 02$ & $7 \cdot 15$ & $10.41,13.63$ & - \\
\hline${ }^{2} \mathrm{H}_{2} \mathrm{O}-\mathrm{AN}-1$ & $0 \cdot 18$ & 0.57 & $0.05,0.31$ & 0.007 & $2 \cdot 30$ & 6.39 & $0.86,3.74$ & 0.002 \\
\hline${ }^{2} \mathrm{H}_{2} \mathrm{O}-\mathrm{AN}-2$ & 0.04 & 0.57 & $-0.09,0.17$ & 0.505 & 0.79 & 0.51 & $-0.67,2.26$ & 0.285 \\
\hline
\end{tabular}

BIA, bioelectrical impedance analysis; BI-1, BIA-based equation of Fjeld et al. ${ }^{(3)}$; BI-2, BIA-based equation of Bocage ${ }^{(4)}$; BI-3, BIA-based equation of Kushner et al. ${ }^{(5)}$; AN-1, anthropometry methods of Mellits \& Cheek $^{(6)} ; \mathrm{AN}-2$, anthropometry methods of Morgenstern et al. ${ }^{(6)}$.

* The $t$ test evaluates the difference of the paired values from zero. 

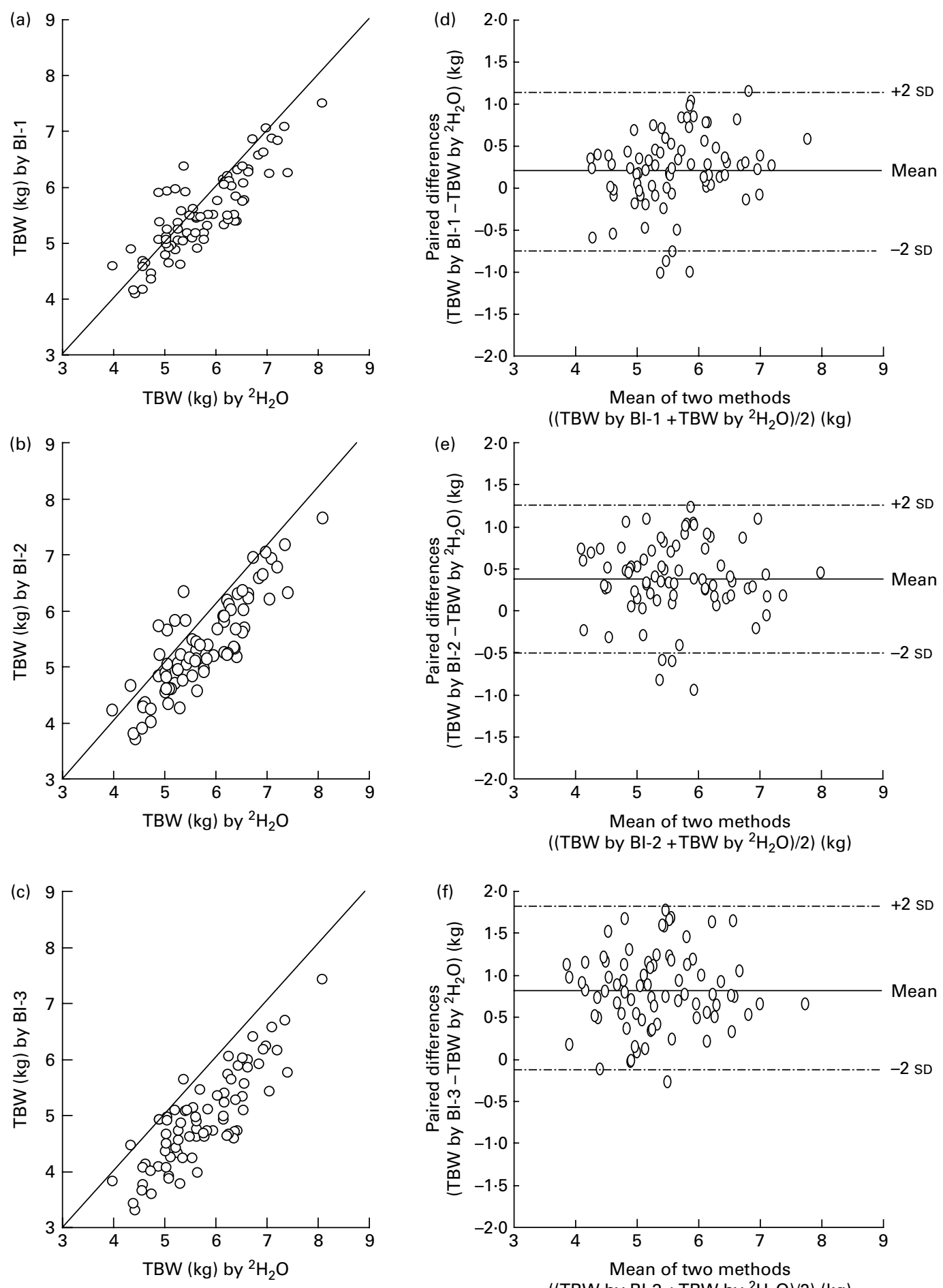

((TBW by BI- $3+$ TBW by $\left.\left.{ }^{2} \mathrm{H}_{2} \mathrm{O}\right) / 2\right)(\mathrm{kg})$

Fig. 1. (a) Individual data points for total body water (TBW) in kg comparing values derived by the reference method $\left({ }^{2} \mathrm{H}_{2} \mathrm{O}\right.$ dilution method) with the bioelectrical impedance analysis (BIA) equation (Fjeld et al. $\left.{ }^{(3)} ; \mathrm{BI}-1\right)$ under study are plotted along the 'line of identity' at the angle of $45^{\circ}\left(R^{2} 0.72\right)$. (b) Individual data points for TBW in kg comparing values derived by the reference method $\left({ }^{2} \mathrm{H}_{2} \mathrm{O}\right.$ dilution method) with the BIA equation (Bocage ${ }^{(4)}$; $\left.\mathrm{BI}-2\right)$ under study are plotted along the line of identity $\left(R^{2} 0.74\right)$. (c) Individual data points for TBW in $\mathrm{kg}$ comparing values derived by the reference method $\left({ }^{2} \mathrm{H}_{2} \mathrm{O}\right.$ dilution method) with the BIA equation (Kushner et al. $\left.{ }^{(5)} ; \mathrm{BI}-3\right)$ under study are plotted along the line of identity $\left(R^{2} 0.71\right)$. (d) Bland-Altman plots of the difference in each participant between TBW in $\mathrm{kg}$ derived by the ${ }^{2} \mathrm{H}_{2} \mathrm{O}$ dilution method and the $\mathrm{BI}-1^{(3)}$ method under study plotted against the average of the TBW in $\mathrm{kg}$ by the ${ }^{2} \mathrm{H}_{2} \mathrm{O}$ method. The solid line and the dotted lines are the mean and 2 SD of the differences, respectively. Mean difference ${ }^{2} \mathrm{H}_{2} \mathrm{O}-\mathrm{BI}-1=0.21$ (SD 0.44$) \mathrm{kg}(P=0.0001$ ). (e) Bland-Altman plots of the difference in each participant between TBW in kg derived by the ${ }^{2} \mathrm{H}_{2} \mathrm{O}$ dilution method and the $\mathrm{BI}-2^{(4)}$ method under study plotted against the average of the TBW in kg by the ${ }^{2} \mathrm{H}_{2} \mathrm{O}$ method. The solid line and the dotted lines are the mean and 2 SD of the differences, respectively. Mean difference ${ }^{2} \mathrm{H}_{2} \mathrm{O}-\mathrm{BI}-2=0.38$ (SD 0.44) kg (P<0.0001). (f) Bland-Altman plots of the difference in each participant between TBW in $\mathrm{kg}$ derived by the ${ }^{2} \mathrm{H}_{2} \mathrm{O}$ dilution method and the $\mathrm{BI}-3^{(5)}$ method under study plotted against the average of the TBW in $\mathrm{kg}$ by the ${ }^{2} \mathrm{H}_{2} \mathrm{O}$ method. The solid line and the dotted lines are the mean and 2 SD of the differences, respectively. Mean difference ${ }^{2} \mathrm{H}_{2} \mathrm{O}-\mathrm{BI}-3=0.82$ (SD 0.47) $\mathrm{kg}(P<0.0001)$. 

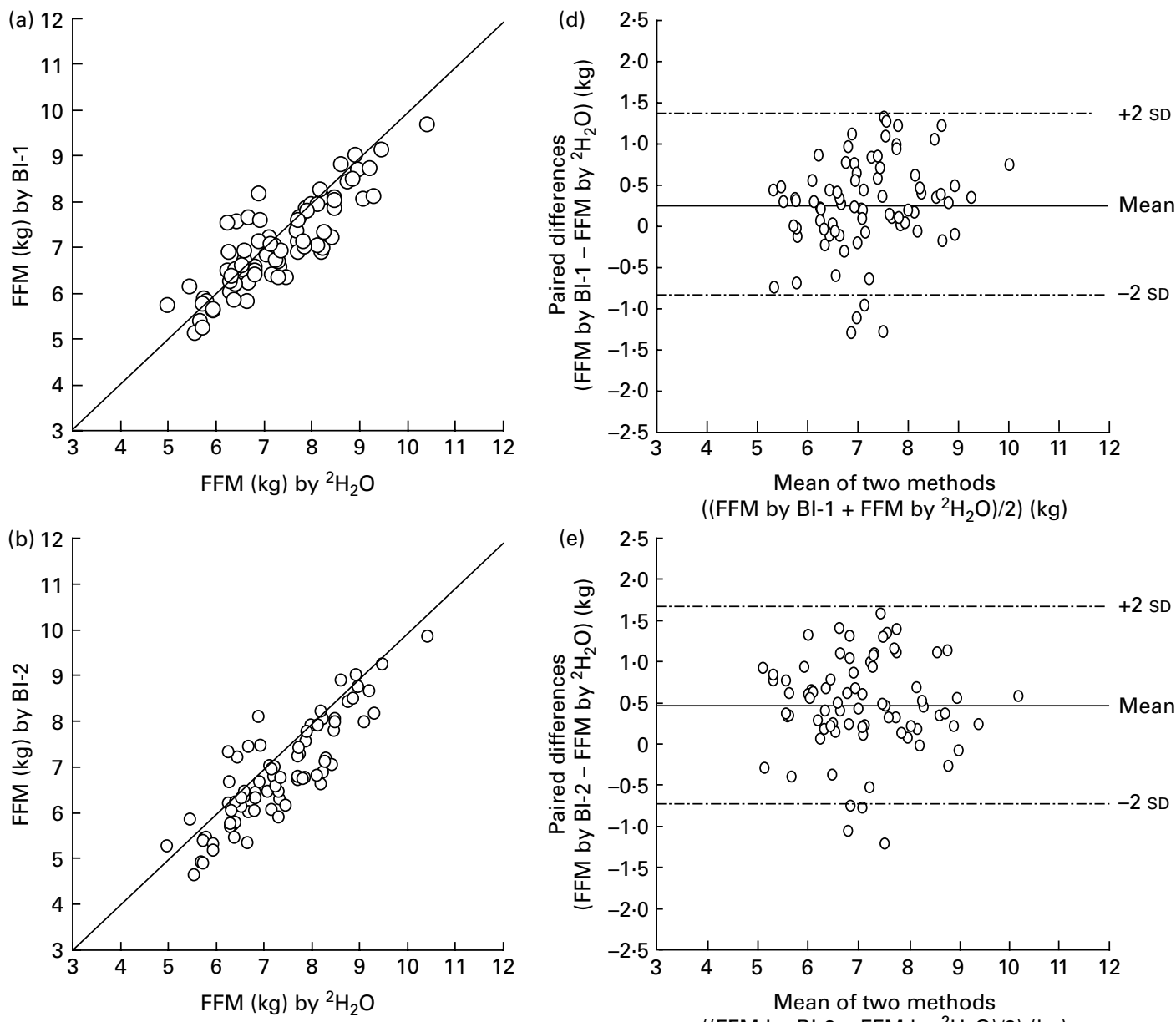

((FFM by BI-2 + FFM by $\left.\left.{ }^{2} \mathrm{H}_{2} \mathrm{O}\right) / 2\right)(\mathrm{kg})$
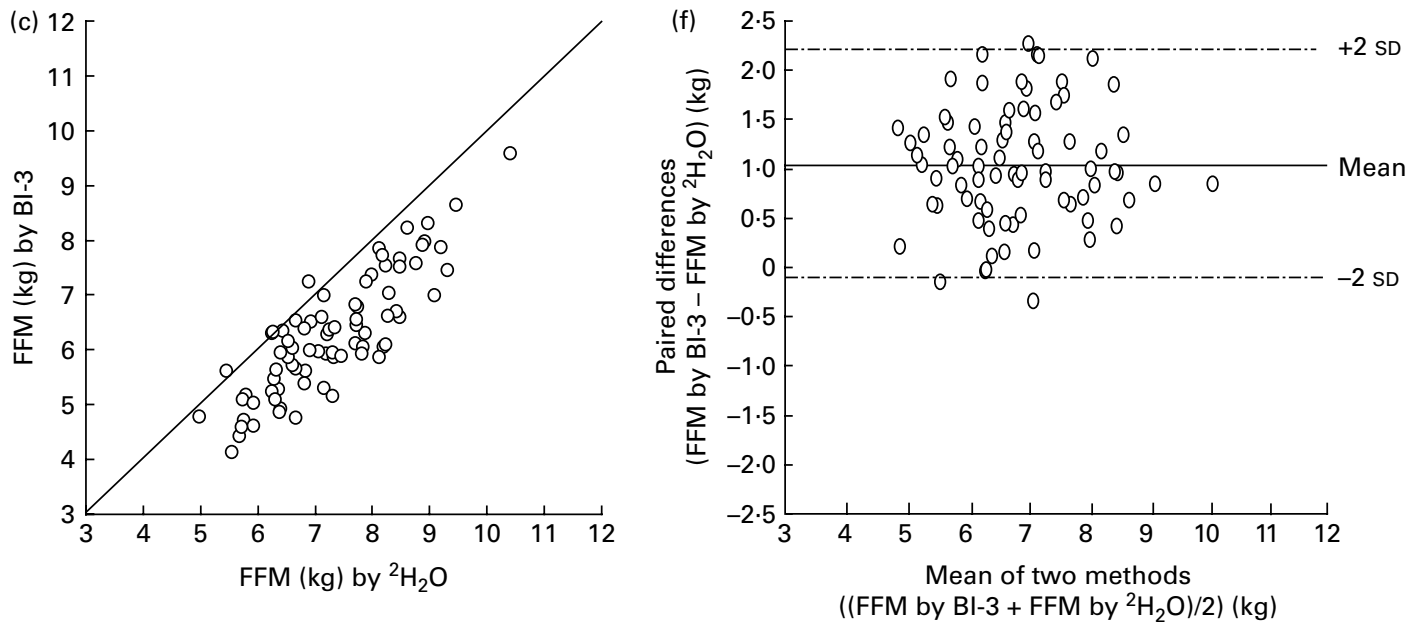

Fig. 2. (a) Individual data points for fat-free mass (FFM) in $\mathrm{kg}$ comparing values derived by the reference method $\left({ }^{2} \mathrm{H}_{2} \mathrm{O}\right.$ dilution method) with the bioelectrical impedance analysis (BIA) equation (Fjeld et al. $\left.{ }^{(3)} ; \mathrm{BI}-1\right)$ under study are plotted along the 'line of identity' at the angle of $45^{\circ}\left(R^{2} 0.74\right)$. (b) Individual data points for FFM in $\mathrm{kg}$ comparing values derived by the reference method $\left({ }^{2} \mathrm{H}_{2} \mathrm{O}\right.$ dilution method) with the BIA equation (Bocage ${ }^{(4)}$; $\left.\mathrm{BI}-2\right)$ under study are plotted along the line of identity $\left(R^{2}\right.$ 0.76). (c) Individual data points for FFM in $\mathrm{kg}$ comparing values derived by the reference method $\left({ }^{2} \mathrm{H}_{2} \mathrm{O}\right.$ dilution method) with the BIA equation (Kushner et al. $\left.{ }^{(5)} ; \mathrm{Bl}-3\right)$ under study are plotted along the line of identity $\left(R^{2} 0.73\right)$. (d) Bland-Altman plots of the difference in each participant between FFM in kg derived by the ${ }^{2} \mathrm{H}_{2} \mathrm{O}$ dilution method and the $\mathrm{Bl}-1^{(3)}$ method under study plotted against the average of the FFM in kg by the ${ }^{2} \mathrm{H}_{2} \mathrm{O}$ method. The solid line and the dotted lines are the mean and $2 \mathrm{SD}$ of the differences, respectively. Mean difference ${ }^{2} \mathrm{H}_{2} \mathrm{O}-\mathrm{BI}-1=0.25$ (SD 0.56$) \mathrm{kg}(P=0.0002)$. (e) Bland-Altman plots of the difference in each participant between FFM in kg derived by the ${ }^{2} \mathrm{H}_{2} \mathrm{O}$ dilution method and the $\mathrm{BI}-2^{(4)}$ method under study plotted against the average of the FFM in $\mathrm{kg}$ by the ${ }^{2} \mathrm{H}_{2} \mathrm{O}$ method. The solid line and the dotted lines are the mean and $2 \mathrm{SD}$ of the differences, respectively. Mean difference ${ }^{2} \mathrm{H}_{2} \mathrm{O}-\mathrm{BI}-2=0.47$ (sD $0.57) \mathrm{kg}(P<0.0001)$. (f) Bland-Altman plots of the difference in each participant between FFM in kg derived by the ${ }^{2} \mathrm{H}_{2} \mathrm{O}$ dilution method and the BI- $3^{(5)}$ method under study plotted against the average of the FFM in $\mathrm{kg}$ by the ${ }^{2} \mathrm{H}_{2} \mathrm{O}$ method. The solid line and the dotted lines are the mean and $2 \mathrm{SD}$ of the differences, respectively. Mean difference ${ }^{2} \mathrm{H}_{2} \mathrm{O}-\mathrm{BI}-3=1.04$ (SD 0.59) $\mathrm{kg}(P<0.0001)$. 

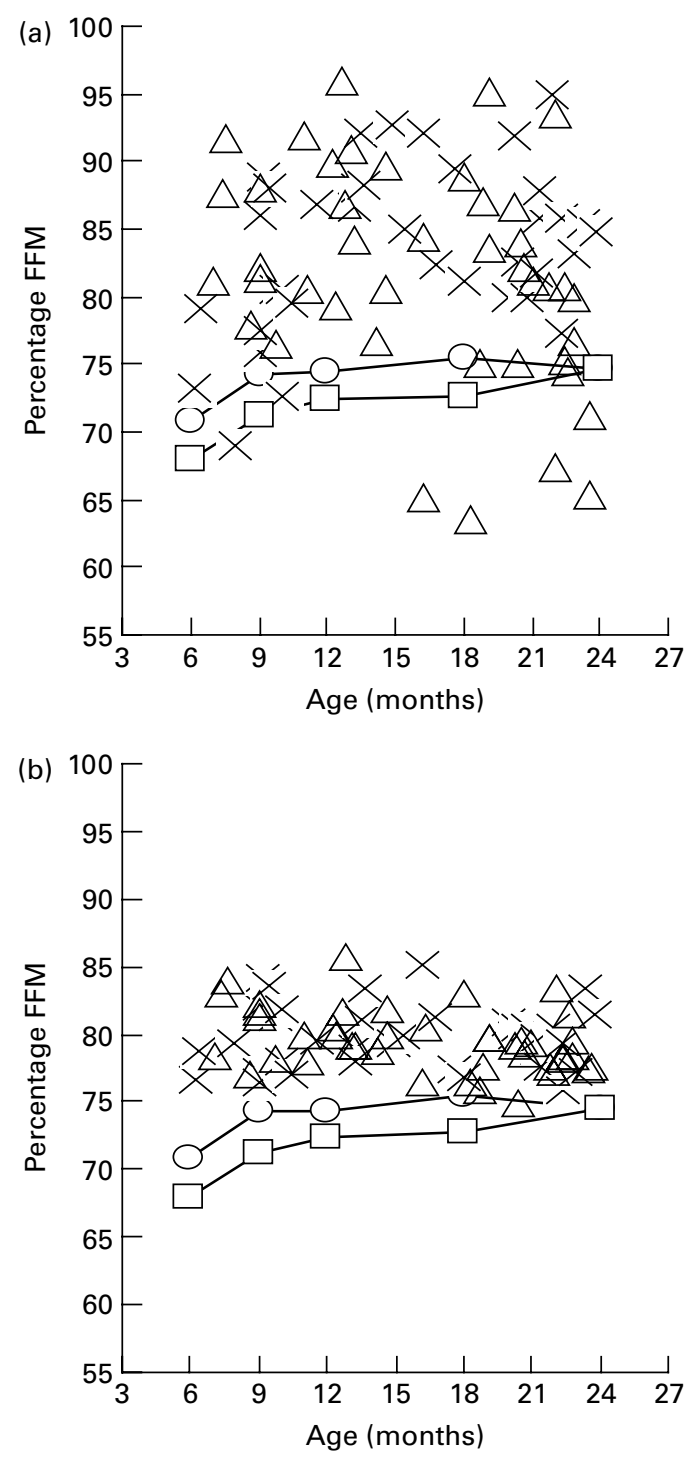

Fig. 3. Individual data points for percentage fat-free mass (FFM) derived by the ${ }^{2} \mathrm{H}_{2} \mathrm{O}$ dilution method (a) and the bioelectrical impedance analysis equation of Fjeld et al. ${ }^{(3)}$ (b) are plotted against age in months. Age- and sex-specific reference values for percentage FFM in healthy American infants derived by multicomponent models (Butte et al. ${ }^{(15)}$ ) are plotted for comparison (data points are connected). $(\times)$, Boys; $(\Delta)$, girls; $(-\bigcirc-)$, boys, Butte et al. ${ }^{(15)} ;(-\square-)$, girls, Butte et al. ${ }^{(15)}$.

respectively. In Fig. 3, individual data points for percentage FFM derived by the BIA equation of Fjeld et al. ${ }^{(3)}$ and by the reference method are plotted against age in months. Age- and sex-specific reference data on percentage FFM in healthy American infants derived by multicomponent models $^{(15)}$ are also plotted in Fig. 3 for comparison. As expected, the percentage FFM was consistently higher than the reference values for healthy infants from the USA.

\section{Discussion}

Recent findings on the association of fetal growth, early postnatal growth and rate of growth in childhood ${ }^{(17-20)}$ with diseases in adults, such as hypertension, type 2 diabetes and $\mathrm{CHD}$, have generated considerable new interest in studying postnatal growth and development. In South Asian countries, the rate of low birth weight is very high ${ }^{(21)}$, largely due to intra-uterine growth retardation. Further, the incidence of hypertension, type 2 diabetes and CHD is high among South Asians $^{(22)}$. Population-based studies on growth and its components such as FFM in infancy should be useful in understanding these phenomena.

Impedance to the flow of current in body tissues is a function of resistance $(\mathrm{R})$ and reactance. Cell membranes act as small capacitors and thus offer a reactive resistance (i.e. reactance) to the flow of current. Based on electrical theory, current at relatively higher frequencies passes through both extracellular and intracellular fluid and can provide an index of TBW. Thus the BIA method can distinguish between non-fat body mass (FFM) and fat mass ${ }^{(23)}$. Of the three BIA-based equations evaluated by us, the one by Fjeld et $a{ }^{(3)}$ was found to give a better prediction of TBW than either of the other two. The BIA equations of Fjeld et al. ${ }^{(3)}$ were derived from thirty Peruvian undernourished children (height-for-weight $z$-score ranged from -3 to $+1 \mathrm{SD}$ ). Their method was similar to ours, except that they used $800 \mu \mathrm{A}$ root mean square (RMS) current and we used $400 \mu \mathrm{A}$ RMS current. As expected, the percentage FFM was consistently higher in the study infants (coming from low socio-economic group families) compared with those in the $\mathrm{USA}^{(6)}$. This is so, by both the BIA methods and the reference method based on ${ }^{2} \mathrm{H}_{2} \mathrm{O}$ dilution.

We, however, note that the difference between FFM derived by the better of the three equations, i.e. of Fjeld et al., and by the reference method is relatively large and equations with better precision are desirable. As stated earlier, the two anthropometry-based equations evaluated on these infants gave better agreement with the reference method than the BIAbased equations ${ }^{(6)}$. FFM derived by the equation of Fjeld et $a l^{(3)}$ underestimates FFM by nearly $3 \%$ and the difference is highly significant (Table 3 ). We have also plotted the mean reference values by age for healthy infants in the USA ${ }^{(15)}$. The latter values were derived by multi-component modelling. As expected, the percentage FFM values were consistently higher for the infants we studied. A question may be raised as to why we need a BIA-based equation where anthropometry-based equations were found to have good predictive ability in this population. The weight- or height-based indices (for example, $\mathrm{BMI}$ ) or prediction equations cannot differentiate lean mass and fat mass ${ }^{(24)}$. There can be a twofold range of variation in fatness for a given BMI value in children ${ }^{(25)}$. That these indices are predictive is due to the fact that the trajectory of growth of lean mass and fat mass usually go together. A problem arises when they take different trajectories. Such is the case for babies in South Asia who have a lower birth weight than their Western counterparts; recent studies have shown that their body fat is relatively preserved, leading to their description as a 'thin-fat' phenotype ${ }^{(22,26)}$, meaning that the fat mass and lean mass follow different trajectories of intra-uterine growth. Studies have also shown that this relatively low body mass with high body fat at birth tracks into childhood ${ }^{(27,28)}$. Further, adult populations in India have a higher percentage of body fat for a given BMI than Western population, suggesting that this thin-fat phenotype tracks into adulthood ${ }^{(29,30)}$. Given the public health importance of this phenomenon, the BIA-based equations for lean mass 
measurement assume relevance. The value of BIA is largely as an epidemiological technique and, here, it is the only predictive technique that estimates lean mass ${ }^{(24)}$. Given that none of the published BIA-based prediction equations for children was found satisfactory we need to develop suitable equations to better predict lean mass in this population.

We used a stable-isotope dilution technique as the reference standard. Isotope-dilution methods use a two-component model to measure FFM and fat mass and are generally safe, reliable, accurate and feasible in infants and children. To derive FFM, one has to use age- and sex-specific hydration factors such as those derived by multicomponent models ${ }^{(15)}$. While the hydration of FFM changes with age and maturation, use of age- and sex-specific hydration factors minimises errors associated with maturation. The hydration factors for FFM proposed earlier for 1- to 5-year-old children give closely similar results ${ }^{(31,32)}$. Measurement of TBW using ${ }^{2} \mathrm{H}_{2} \mathrm{O}$ dilution methods has been used as a reference method in many of the classic studies of body composition in children $^{(32-35)}$.

As discussed earlier, valid equations based on BIA should assist in-depth studies to understand the early origin (i.e. fetal, neonatal and early childhood) of adult diseases of pubic health importance such as, diabetes, hypertension and CHD. Based on skinfold measurement, Yajnik et al. ${ }^{(26)}$ have shown that Indian babies are not only small at birth but they also have less muscle mass and relatively more fat mass; the so called 'thin-fat baby' syndrome ${ }^{(22,26)}$. They further showed that thin-fat babies grow up to become thin-fat adults with thinner limbs and high waist:hip ratio; they appear to be fetally programmed and predisposed to diabetes. He also showed that the smallness and thinness of Indian babies is present at birth and an unusual thin-fat body composition is associated with the insulin resistance syndrome ${ }^{(19)}$.

To conclude, the best of the three published BIA-based equations, i.e. by Fjeld et al. ${ }^{(3)}$, gave an estimate of the mean FFM that was 2.98 (95\% CI 1.57, 4.40) \% lower than that by the reference ${ }^{2} \mathrm{H}_{2} \mathrm{O}$ method. Better equations for estimating FFM in South Asian infants are desirable. Development of new equations derived from population-specific data such as ours should be worthwhile.

\section{Acknowledgements}

This research received no specific grant from any funding agency in the public, commercial or not-for-profit sectors.

We thank Md. Jakir Hossain for statistical assistance.

B. S., a research fellow, carried out the study procedures, took part in the analysis and in writing the manuscript. D. M. conceived of the study design, experiment, ${ }^{2} \mathrm{H}_{2} \mathrm{O}$ dilution test and statistical analysis, supervised B. S.'s work, took part in data analysis and interpretation and in writing the manuscript. S. S. assisted B. S. in standardisation of procedures for anthropometry and ${ }^{2} \mathrm{H}_{2} \mathrm{O}$ dilution. S. S. also took part in study design, analysis and interpretation of the findings. A. V. $K$. carried out the ${ }^{2} \mathrm{H}_{2} \mathrm{O}$ analysis in the laboratory, took part in the interpretation of the findings, and in critically reviewing the manuscript. K. B. took part in the study design, secondary supervision, interpretation and preparing the manuscript.

None of the authors has any conflict of interest to declare.

\section{References}

1. Mellits ED \& Cheek DB (1970) The assessment of body water and fatness from infancy to adulthood. Monogr Soc Res Child Dev 35, 12-26.

2. Morgenstern BZ, Mahoney DW \& Warady BA (2002) Estimating total body water in children on the basis of height and weight: a reevaluation of the formulas of Mellits and Cheek. J Am Soc Nephrol 13, 1884-1888.

3. Fjeld CR, Freundt-Thurne J \& Schoeller DA (1990) Total body water measured by ${ }^{18} \mathrm{O}$ dilution and bioelectrical impedance in well and malnourished children. Pediatr Res 27, 98-102.

4. Bocage C (1988) Impedance measurement of body composition in children. MSc Thesis, University of West Indies, Kingston, Jamaica.

5. Kushner RF, Schoeller DA, Fjeld CR, et al. (1992) Is the impedance index $\left(\mathrm{ht}^{\wedge} 2 / \mathrm{R}\right)$ significant in predicting total body water? Am J Clin Nutr 56, 835-839.

6. Sen B, Mahalanabis D, Shaikh S, et al. (2009) Evaluation of equations for fat free mass based on anthropometry in infants and young children in South Asia. Br J Nutr 101, 551-557.

7. Anonymous (1992) Bioelectrical impedance and body composition. Lancet 340, 1511.

8. Pocock SJ (1999) Clinical Trials: A Practical Approach, pp. 123-138. New York: John Wiley, Sons.

9. Nyboer J (1972) Workable volume and flow concepts of bio-segments by electrical impedance plethysmography. TIT $J$ Life Sci 2, 1-13.

10. Deurenberg P, Weststrate JA, Paymans I, et al. (1988) Factors affecting bioelectrical impedance measurements in humans. Eur J Clin Nutr 42, 1017-1022.

11. Deurenberg P, van der Kooy K, Leenen R, et al. (1989) Body impedance is largely dependent on the intra- and extra-cellular water distribution. Eur J Clin Nutr 43, 845-853.

12. Lohman TG, Roche AF \& Martorell R (1998) Anthropometric Standarization Reference Mannual, pp. 55-70 [TG Lohman, AF Roche and R Martorell, editors]. Champaign, IL: Human Kinetic Books.

13. Cameron N (2004) Measuring growth. In Methods in Human Growth Research, pp. 68-107 [RC Hauspie, N Cameron and L Molinari, editors]. Cambridge: Cambridge University Press.

14. Shaikh S, Mahalanabis D, Kurpad AV, et al. (2002) Validation of an anthropometric equation and bioelectrical impedance analysis (BIA) technique to measure body composition of children in India using $\mathrm{D}_{2} \mathrm{O}$ dilution method. Nutr Res 22, 685-694.

15. Butte NF, Hopkinson JM, Wong WW, et al. (2000) Body composition during the first 2 years of life: an updated reference. Pediatr Res 47, 578-585.

16. Bland JM \& Altman DG (1986) Statistical methods for assessing agreement between two methods of clinical measurement. Lancet i, 307-310.

17. Barker DJ, Eriksson JG, Forsen T, et al. (2002) Fetal origins of adult disease: strength of effects and biological basis. Int $J$ Epidemiol 31, 1235-1239.

18. Singhal A \& Lucas A (2004) Early origins of cardiovascular disease: is there a unifying hypothesis? Lancet 363, 1642-1645.

19. Yajnik CS (2004) Early life origins of insulin resistance and type 2 diabetes in India and other Asian countries. $J$ Nutr 134, 205-210.

20. Lucas A \& Sampson HA (2006) Infant nutrition and primary prevention: current and future perspectives. Nestlé Nutr Workshop Ser Pediatr Program 57, 1-13.

21. Black RE, Allen LH, Bhutta ZA, et al. (2008) Maternal and child undernutrition: global and regional exposures and health consequences. Lancet 371, 243-260. 
22. Yajnik CS, Lubree HG, Rege SS, et al. (2002) Adiposity and hyperinsulinemia in Indians are present at birth. $J$ Clin Endocrinol Metab 87, 5575-5580.

23. Tang W, Ridout D \& Modi N (1997) Assessment of total body water using bioelectrical impedance analysis in neonates receiving intensive care. Arch Dis Child Fetal Neonatal Ed 77, F123-F126.

24. Wells JC \& Fewtrell MS (2006) Measuring body composition. Arch Dis Child 91, 612-617.

25. Wells JC (2000) A Hattori chart analysis of body mass index in infants and children. Int J Obes Relat Metab Disord 24, 325-329.

26. Yajnik CS, Fall CH, Coyaji KJ, et al. (2003) Neonatal anthropometry: the thin-fat Indian baby. The Pune Maternal Nutrition Study. Int J Obes Relat Metab Disord 27, 173-180.

27. Krishnaveni GV, Hill JC, Veena SR, et al. (2005) Truncal adiposity is present at birth and in early childhood in South Indian children. Indian Pediatr 42, 527-538.

28. Bavdekar A, Yajnik CS, Fall CH, et al. (1999) Insulin resistance syndrome in 8-year-old Indian children: small at birth, big at 8 years, or both? Diabetes 48, 2422-2429.
29. Dudeja V, Misra A, Pandey RM, et al. (2001) BMI does not accurately predict overweight in Asian Indians in northern India. Br J Nutr 86, 105-112.

30. WHO Expert Consultation (2004) Appropriate body mass index for Asian populations and its implications for policy and intervention strategies. Lancet 363, 157-163.

31. Ziegler EE, O'Donnell AM, Nelson SE, et al. (1976) Body composition of the reference fetus. Growth 40, 329-341.

32. Fomon SJ, Haschke F, Ziegler EE, et al. (1982) Body composition of reference children from birth to age 10 years. Am J Clin Nutr 35, 1169-1175.

33. Wells JC, Fuller NJ, Dewit O, et al. (1999) Four-component model of body composition in children: density and hydration of fat-free mass and comparison with simpler models. Am J Clin Nutr 69, 904-912.

34. Forbes G (1987) Human Body Composition: Growth, Aging, Nutrition and Activity. New York: Springer-Verlag.

35. Fomon SJ \& Nelson SE (2002) Body composition of the male and female reference infants. Annu Rev Nutr 22, $1-17$. 